\title{
RFID Based Automated Billing System Using Zigbee Embedded Into Shopping Cart
}

\author{
Sowmyashree M S ${ }^{1}$, Saritha I G ${ }^{2}$, Thejaswini $\mathrm{S}^{3}$, Surekha R Gondkar ${ }^{4}$ \\ Department of Telecommunication Engineering, BMSIT $T^{1,2,3,4}$ \\ Assistant prof ${ }^{1,2,3}$, Associate prof ${ }^{4}$.
}

\begin{abstract}
Large grocery stores are nowadays used by millions of people for the acquisition of an enlarging number of products. Product acquisition represents a complex process that comprises time spent in corridors, product location and checkout queues. On the other hand, it is becoming increasingly difficult for retailers to keep their clients loyal and to predict their needs due to the influence of competition and the lack of tools that discriminate consumption patterns. This paper gives the proposal of an architecture and solution of an innovative system for the acquisition of products in grocery stores (Intelligent Cart). Every shopping cart will have a RFID reader. As the shopper put the items one by one into the cart the RFID will read the data and the microcontroller adds the total and displays the same on the LCD. When the shopping is done all that the user needs to do is pressing the END shopping button. When this is done the total is sent to the billing system using Zigbee transceivers along with the unique cart number.

At this moment the data is sent to all the counters and whichever counter is free, he will enter the counter number against the cart number and the bill and this will then be displayed in the shopping cart. The machine keeps the bill ready and now all that the user needs to do is to pay the bill and walk out of the shop.

Index Terms: Zigbee, RFID, keiluvision, flash magic, microcontroller
\end{abstract}

\section{INTRODUCTION}

In recent years a deep structural change has occurred, with consequences on economic growth and society, especially in factors such as territorial occupation, urbanization, openness to global markets, demography, family structures, cultural \& consuming patterns. Innovation in communication and information technologies have caused a revolution in values, knowledge and perceptions in practically all areas of human understanding, deeply carving the so-called "Age of Information and Knowledge".

The grocery industry sector is nowadays extremely important in worldwide economy, with its recent evolution in technological, political, social and economic terms making it one of the most convenient and diverse businesses across the globe. The emergence of new business models made possible due to the new technologies and to the development of new economies that can be used to understand and value the ubiquitous commerce activity. The challenges and opportunities created by electronic business in the supply chain have caused the sharing of information between business partners to improve operational performance, consumer service and solution development.

Businesses have evolved from the sharing and coordination of information to the sharing of knowledge and advanced cooperation practices. The emergence of new technologies, such as Radio Frequency Identification (RFID) and wireless networks, makes the traditional retail processes faster, transparent and efficient. The technology represents to retailers and opportunity to reduce costs and to improve services, allowing to attend clients quickly, precisely and supplying personalised services. The advances in manufacturing, distribution and information combined with the urbanization of modern society and sociodemographical changes created the so-called new consumer. The consumer has a deeper understanding in comparing product costs, is more versatile in brand preferences, shows little loyalty to retailers, has great expectations in services and client regard, is self-sufficient and is more demanding towards supplied information.

There was a clear control transference from the manufacturers and retailers to the consumer. Strong competition between larger retail chains caused the minimization of profit margins as a form of keeping aggressive prices and winning more clients. Today, this is no longer enough. One has to bet on offer differentiation and in the adoption of client retention strategies through the strengthening of the relation with the consumer, allowing adequate answers to clients' needs through personalized service and promotion plans that augment their satisfaction and, most importantly, their enthusiasm.

When you enter the store, there are, generally, no employees to help you. At most times, the only people in the store are customers. If you show up between 3 and 6 a.m., you might see employees performing shelf-stocking activities. A clean-up crew shows up at 6:30a.m. 
So in all these perception, an intelligent cart which guides the customer with all the facilities which is required for it to be a customer-friendly is designed in this paper.

\section{Working}

An embedded system will be placed on trolleys in the mall. it will consist of rfid reader. all the items in the mall will be equipped with rfid tags. when person put any item in the trolley its code will be detected and the price of that item will be stored in memory. as we put the items the costs will get added to total. thus the billing will be done at the trolley itself. item name and its cost will be displayed on lcd. for detecting different items rfid reader will be used. lcd used will be $16 \times 2$ alphanumeric displays. it will be used to display item names, item cost etc. at the billing counter the total bill data will be transferred to pc by wireless zigbee modules. later the billing is carried out by master section

\section{Block Diagram at Shopping Cart End}

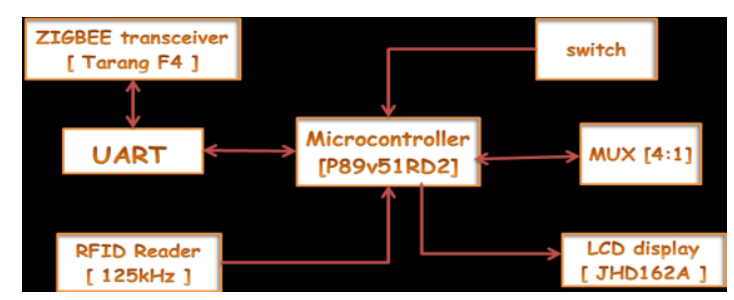

The heart of our system is 8051 based microcontroller, here we are using Philip's P89V51RD2 microcontroller to control all the functions of the system.

RFID tags are used to identify each product of the store uniquely \& hence tagged to each product. A RFID Reader is used in the shopping cart to read the data of product.

Based on Zigbee's local networking functions, in this project we are displaying the product data and the total amount in the PC. Zigbee transceiver modules will communicate with the microcontroller (shopping cart) and PC (counter end) wirelessly.

A switch for cancelation of products is also available .Display device used here is LCD in shopping cart. VB.net software is used to input the data via PC that is to be displayed.

\section{Block Diagram at Counter End}

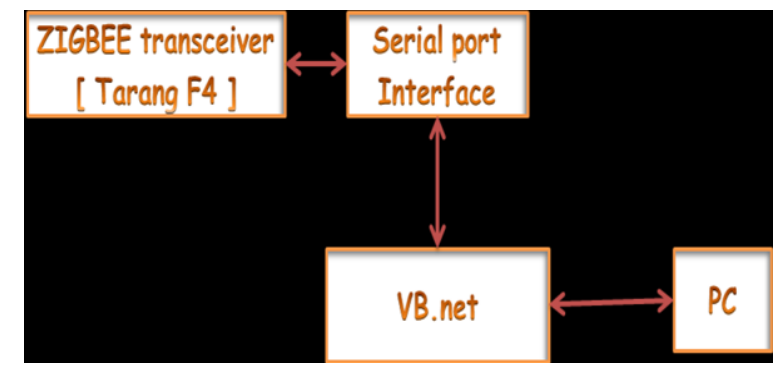

\section{Components Used}

\section{Microcontroller}

The P89V51RD2 is an 80C51 microcontroller with $64 \mathrm{kB}$ Flash and 1024 bytes of data RAM. A key feature of the P89V51RD2 is its X2 mode option. The design engineer can choose to run the application with the conventional 80C51 clock rate (12 clocks per machine cycle) or select the X2 mode (6 clocks per machine cycle) to achieve twice the throughput at the same clock frequency. Another way to benefit from this feature is to keep the same performance by reducing the clock frequency by half, thus dramatically reducing the EMI. The Flash program memory supports both parallel programming and in serial In-System - (ISP). Parallel programming mode offers gang-programming at high speed, reducing programming costs and time to market. ISP allows a device to be reprogrammed in the end product under software control. The capability to field/update the application firmware makes a wide range of applications possible.

The P89V51RD2 is also In-Application Programmable (IAP), allowing the Flash program memory to be reconfigured even while the application is running. Microcontroller is a computer on a single chip (IC), designed with all the in built facilities, both software and hardware, to control and /or monitor any device, process, equipment, machine, In general electronics, electrical, electro mechanical systems applicable to variety 
of industries. With such a huge applications for Micro controllers, the market of them is vast. And thus many versions of micro controllers from the different manufacturers are Intel, Zilog, Toshiba, Sharp, Motorola, Microchip, Atmel and Philips.

\section{LCD DISPLAY}

A liquid crystal display is a thin, flat electronic visual display that uses the light modulating properties of liquid crystals (LCs).

\section{PROGRAMMING OF LCD}

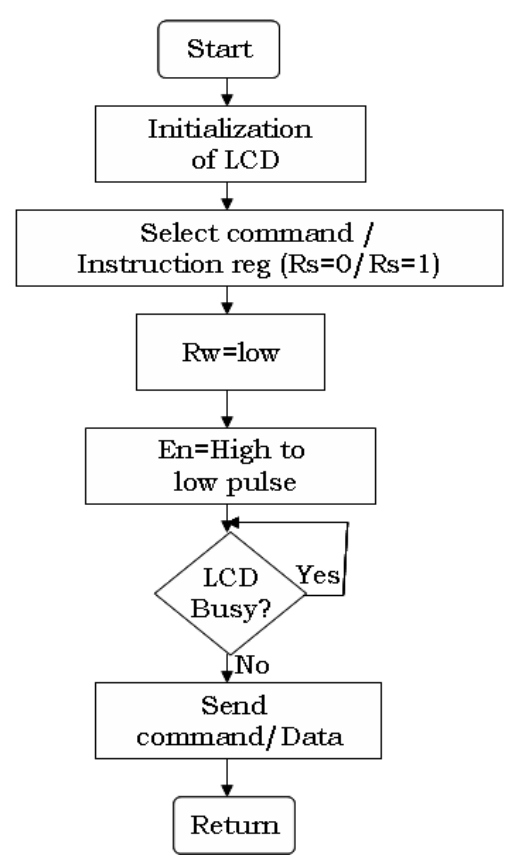

\section{SWITCH}

Push Button Switches consist of a simple electric switch mechanism which controls some aspect of a machine or a process. Buttons are typically made out of hard material such as plastic or metal. The surface is usually shaped to accommodate the human finger or hand, so the electronic switch can be easily depressed or pushed. It works on the principle called push-to-make or push-to break. the "push-to-make" (normally-open or NO) mechanism are a type of push button electrical switch that operates by the switch making contact with the electronic system when the button is pressed and breaks the current process when the button is released. A "push-to-break" (or normally-closed or NC) electronic switch, on the other hand, breaks contact when the button is pressed and makes contact when it is released.

\section{Multiplexer}

The CD4052B is a differential 4-Channel multiplexer having two binary control inputs, A and B, and an inhibit input. The two binary input signals select 1 of 4 pairs of channels to be turned on and connect the analog inputs to the outputs.

\section{System Design}

Operational frame work of this paper can be divided into two major parts which is shown below

\section{SHOPPING CART SECTION}

The heart of our system is 8051 based microcontroller, here we are using Philip's P89V51RD2 microcontroller to control all the functions of the system.

RFID tags are used to identify each product of the store uniquely \& hence tagged to each product. A RFID Reader is used in the shopping cart to read the data of product.

Based on Zigbee's local networking functions, in this project we are displaying the product data and the total amount in the PC. Zigbee transceiver modules will communicate with the microcontroller (shopping cart) and PC (counter end) wirelessly. 
Display device used here is LCD in shopping cart. VB.net software is used to create and maintain the database at the billing counter.

At the billing counter, the VB.net application is created which has menu and exit options which are used to manipulate the entries in the database. As soon as we turn ON the device the LCD should display a WELCOME message on the LCD panel.

If the customer presses "RESET" button, he should be now able to purchase as many as products as he need by scanning each product.

If he don't need any product which he has already purchased, then he should press the cancel switch that is mounted on the trolley and shall scan the card once again and place the product back which deducts the amount from the total amount.

In case the customer has scanned a product which is expired, then the LCD displays "CANCEL YOUR PREVIOUS EXPIRED PRODUCT". The customer then has to press the cancel switch and remove the product from the trolley.

When the product is scanned, the RFID number is compared against the numbers saved in the database then the corresponding product name, cost and the expiry date will be displayed on the LCD panel.

Since we have two transmitters but microcontroller has only one transmitter pin we make use of 4:1 MUX, where the select line input to the MUX is given from the microcontroller and other two inputs are outputs of RFID reader and ZIGBEE and output is given to transmitter pin of the microcontroller

\section{BILLING SECTION}

We make use of VB.net application for billing purpose and for data base creation and updation.

Once the application is opened we get two options, MENU and EXIT. When we select the MENU option, it provides four options

\section{- $\quad$ Add products}

- $\quad$ Add customers

- $\quad$ Billing details

- $\quad$ Change products

When we select add product option, we can add new product details like product name, product cost, RFID number and expiry date to the database. We can also add customer details like customer name and their phone number using add customer option. Similarly any changes in the products can also be updated in the database using change product option.

However to view the bill of the customer we select billing details option under menu, wherein it asks for PORT number to which the ZIGBEE is connected, the max BAUD RATE which microcontroller supports and to establish communication with ZIGBEE we click on OPEN .

When the trolley section is switched on the ZIGBEE at the trolley verifies the connection by showing PC TESTED message. The computer in response to this displays CONNECTION OK message. Hence the system is ready for wireless communication.

Once the RFID tag is scanned at trolley section, the corresponding details are displayed on the billing details window. The window also shows the number items dropped into the trolley and the total amount. We have implemented encoding techniques to distinguish the different trolleys. As an example, the RFID number is encoded with alphabets such as $\mathrm{N}$ for addition and $\mathrm{C}$ for cancellation of the products.

\section{Results}

The practical result obtained was same as the expected result. RFID based automated billing system embedded into shopping cart was able to perform the following operations successfully.

\section{$\checkmark \quad$ Display a welcome message.}

As soon as the device is turned "ON" the LCD panel attached to the Microcontroller displays a "WELCOME" message as shown.

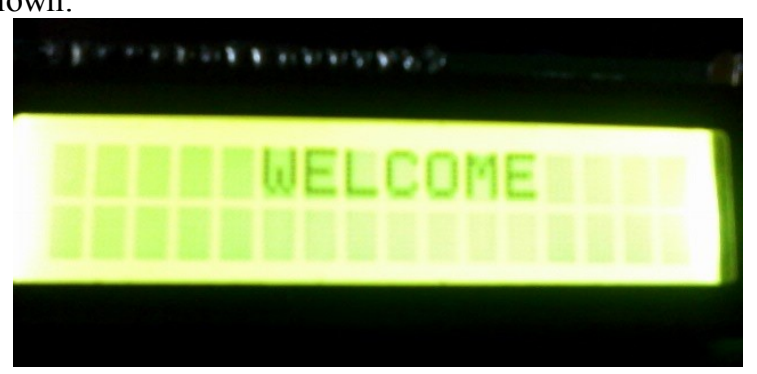




\section{$\checkmark \quad$ Display drop your product message}

soon after the welcome message, it displays drop your product message to the customer where in the default values of total amount and expiry date are displayed as zero.

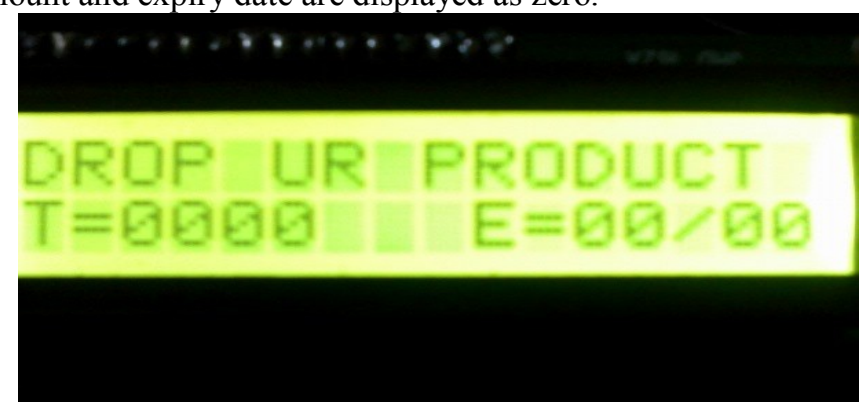

\section{$\checkmark \quad$ Displays RFID tag number}

When the customer drops the product into the trolley, the RFID tag number is displayed.

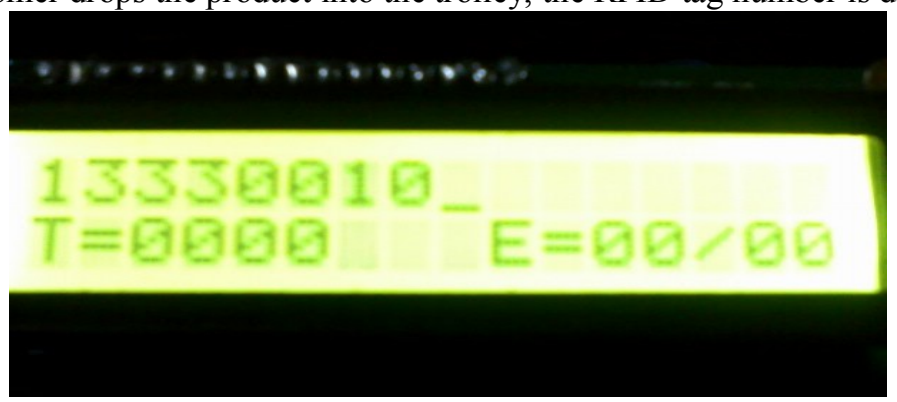

$\checkmark \quad$ Displays product details

The corrsponding product details of the RFID tag are displayed.

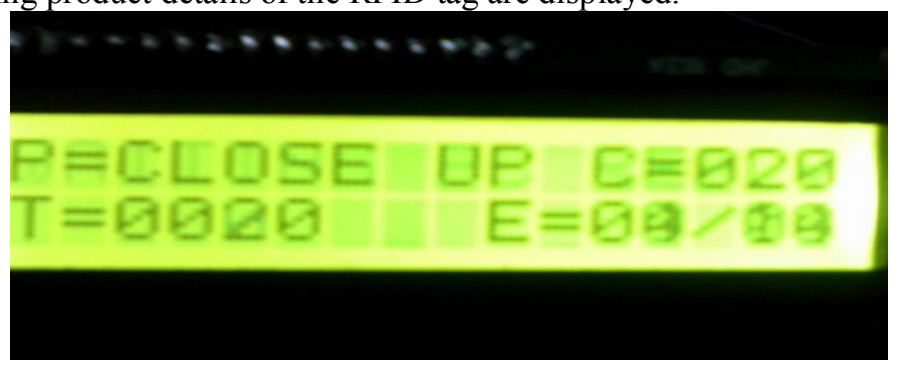

\section{Displays expired product details}

If the product which has expired is dropped into the trolley, the product details with the expiry date is displayed.

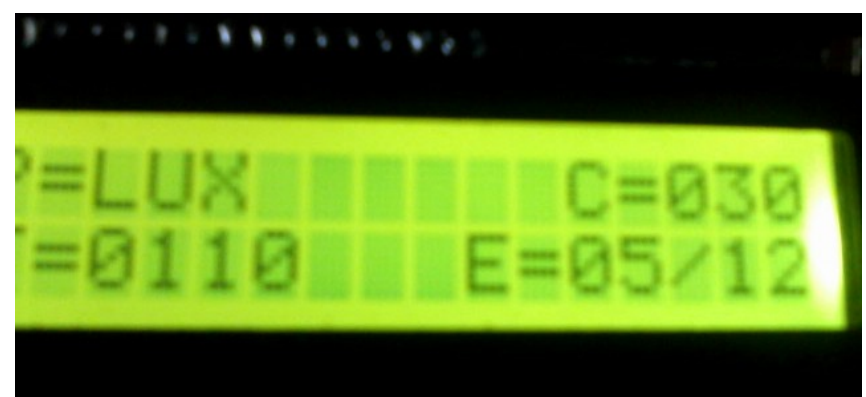

Followed by which the message "CANCEL PREVIOUS EXPIRED PRODUCT". The system freezes until the product is removed. 


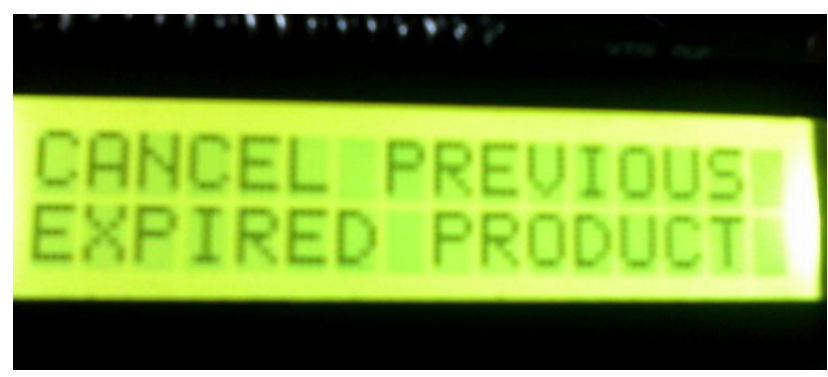

\section{$\checkmark \quad$ Displays drop your product}

Once the expired product is removed, then the system resumes and displays drop your product indicating that the shopping can be continued.



The corresponding outputs in the VB.Net window at the cart end are as shown below.



2 Connection establishment of trolley and cart Zigbees

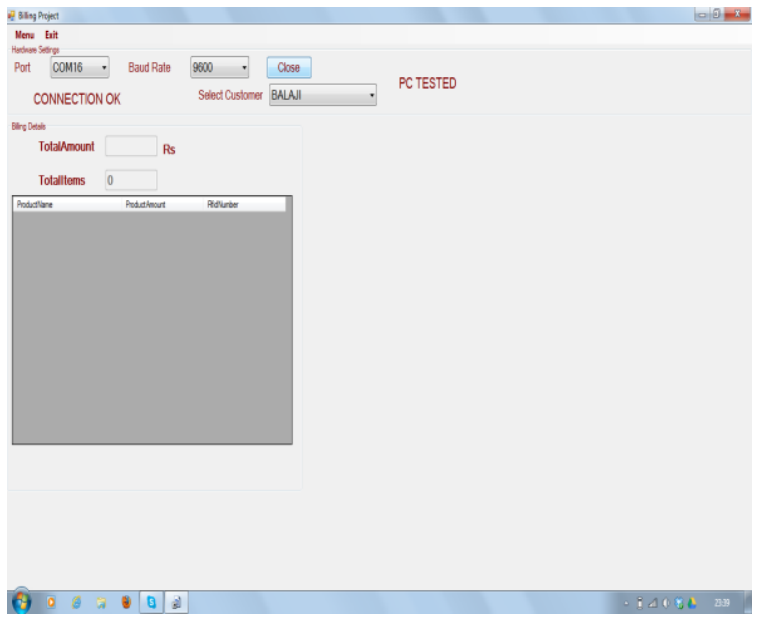


3 Products scanned



4 Removal of expired product or by choice

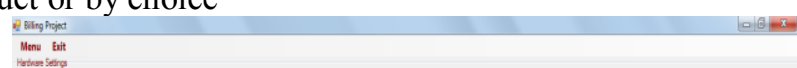


N133300105

Ansoust$$
\text { towath }
$$$$
\text { TotalAmount } 0020 \text { Rs }
$$

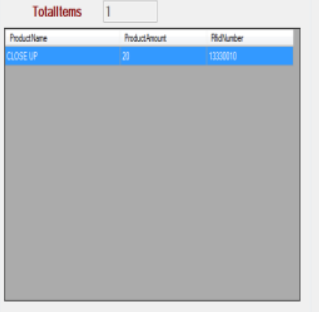

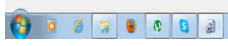

5 addition of new product

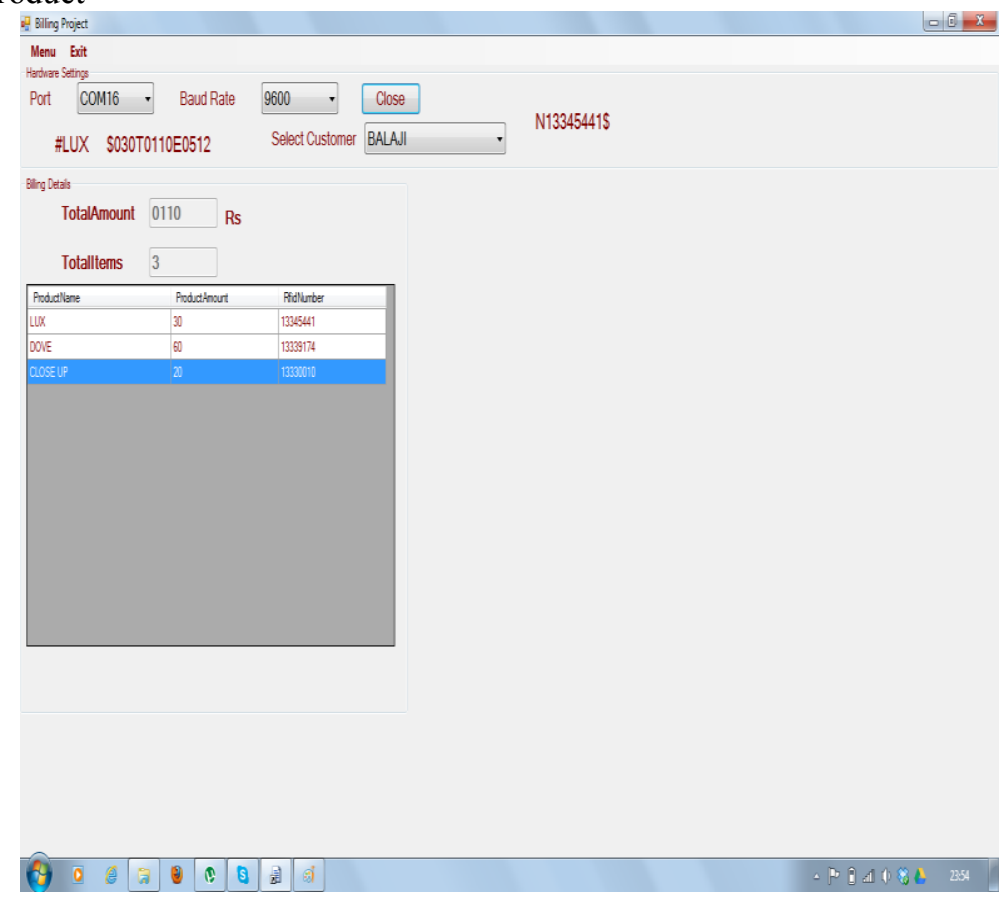


A hardware built is as shown below
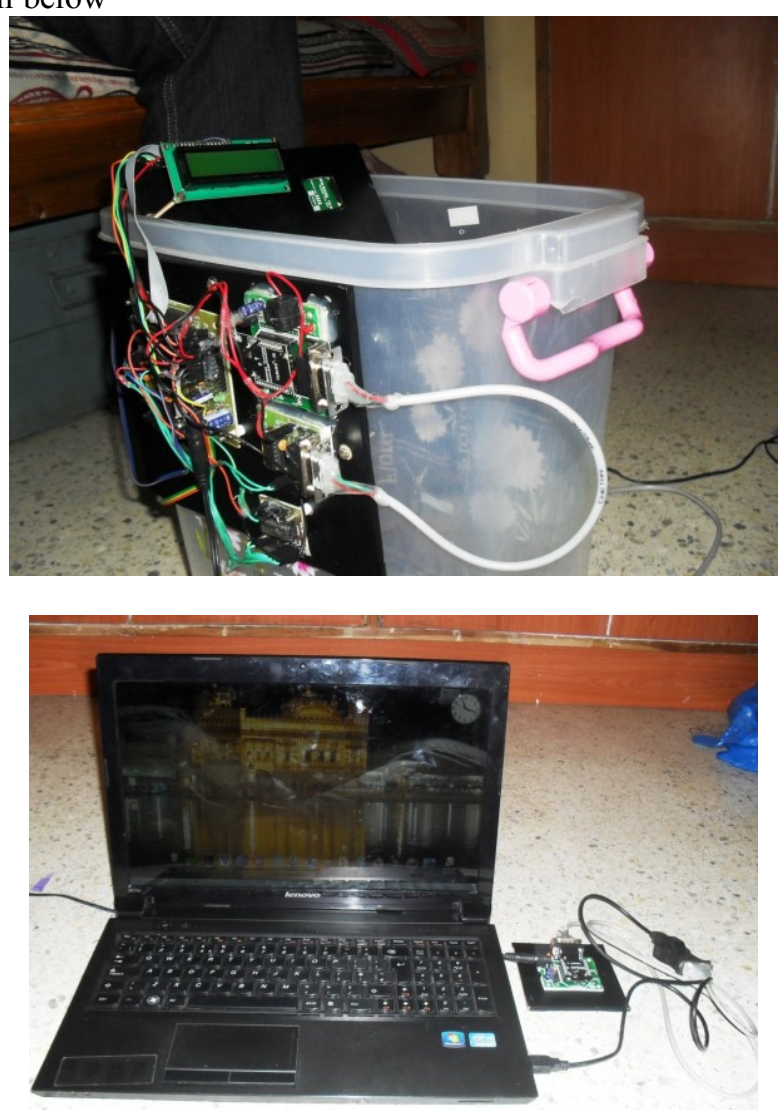

\section{Future Scope}

We believe in "RENOVATION" is as important as "INNOVATION", and keeping this in mind, we had some more features that we could not implement in our project but can be included to enhance it. Some of them are,

Using a GSM module, we can transfer the bill to the mobile instead of printing it. This saves paper.

$>$ With E-banking o net banking enabled, the need of paying bill can also be eliminated, in which case the billing which was already dynamic can also be made mobile.

$>$ There can be voice assistance included.

$>$ Robotic ARM can used for picking and dropping products in which case theft can be avoided.

\section{REFERENCES}

[1] Mazidi, Mazidi, McKinlay- "The 8051 microcontroller and Embedded Systems".

[2] Doukidis, G. \& Pramatari, K.- "Supply Chains of the Future and Emerging Consumer-Based Electronic Services"

[3] Milan Verle- "Architecture \& programming of 8051 ".

[4] A Hand book- "Fundamentals \& applications in RFID appplications"

[5] Savi Technologies. "Active and Passive RFID: Two Distinct, But Complementary, Technologies for Real-Time Supply Chain Visibility, SAVI Technology."

[6] http://www.docstoc.com/docs/24652665/Recommended-Practices-Guide-For-Securing-ZigBee-Wireless-Networks

[7] http://www.digi.com/technology/rf-articles/wireless-zigbee.jsp

[8] http://www.edaboard.com/ftopic58756.html

[9] http://en.wikipedia.org/wiki/ZigBee

[10] http://en.wikipedia.org/wiki/ZigBee_specification

[11] http://www.engineersgarage.com/

[12] http://www.electronicaestudio.com/docs/JHD204ASERIES.pdf

[13] http://www.nskelectronics.com/ 